\title{
Development of a Long-Life-Cycle, Highly Water-Resistant Solar Reflective Retrofit Roof Coating
}

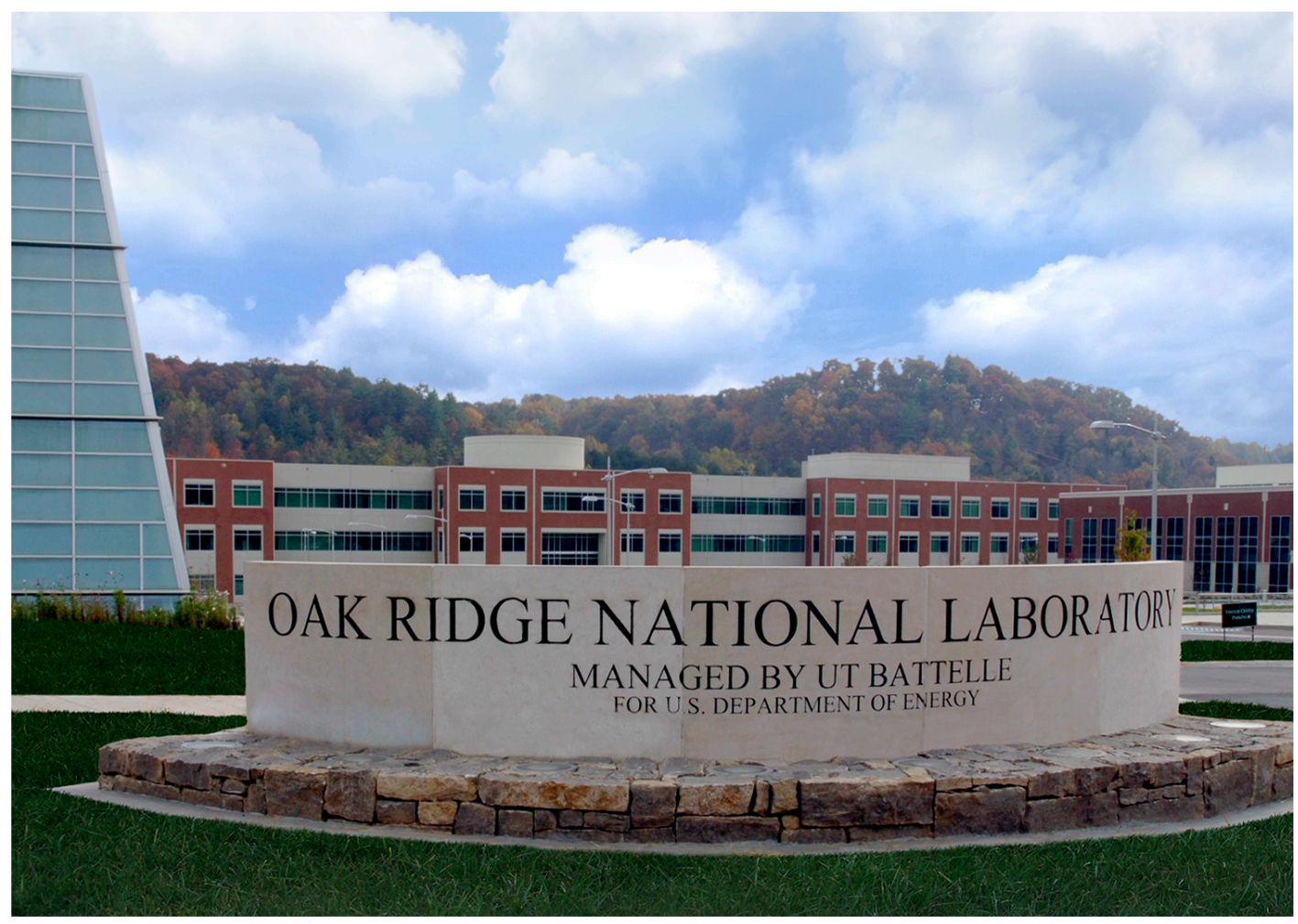

\section{CRADA final report for CRADA number NFE-12-04205}

Approved for public release. Distribution is unlimited.
Georgios Polyzos, ORNL Scott R. Hunter, ORNL Jaswinder Sharma, ORNL Mengdawn Cheng, ORNL Sharon S. Chen, LBNL Victoria Demarest, Dow William Fabiny, Dow Hugo Destaillats, LBNL Ronnen Levinson, LBNL

Date March 4, 2016 


\section{DOCUMENT AVAILABILITY}

Reports produced after January 1, 1996, are generally available free via US Department of Energy (DOE) SciTech Connect.

Website http://www.osti.gov/scitech/

Reports produced before January 1, 1996, may be purchased by members of the public from the following source:

National Technical Information Service

5285 Port Royal Road

Springfield, VA 22161

Telephone 703-605-6000 (1-800-553-6847)

TDD 703-487-4639

Fax 703-605-6900

E-mail info@ntis.gov

Website http://www.ntis.gov/help/ordermethods.aspx

Reports are available to DOE employees, DOE contractors, Energy Technology Data Exchange representatives, and International Nuclear Information System representatives from the following source:

Office of Scientific and Technical Information

PO Box 62

Oak Ridge, TN 37831

Telephone 865-576-8401

Fax 865-576-5728

E-mail reports@osti.gov

Website http://www.osti.gov/contact.html

This report was prepared as an account of work sponsored by an agency of the United States Government. Neither the United States Government nor any agency thereof, nor any of their employees, makes any warranty, express or implied, or assumes any legal liability or responsibility for the accuracy, completeness, or usefulness of any information, apparatus, product, or process disclosed, or represents that its use would not infringe privately owned rights. Reference herein to any specific commercial product, process, or service by trade name, trademark, manufacturer, or otherwise, does not necessarily constitute or imply its endorsement, recommendation, or favoring by the United States Government or any agency thereof. The views and opinions of authors expressed herein do not necessarily state or reflect those of the United States Government or any agency thereof. 
ORNL/TM-2016/132

CRADA/NFE-12-04205

Energy and Transportation Science Division

\title{
DEVELOPMENT OF A LONG-LIFE-CYCLE, HIGHLY WATER-RESISTANT, SOLAR REFLECTIVE RETROFIT ROOF COATING
}

Georgios Polyzos, ORNL

Scott R. Hunter, ORNL

Jaswinder Sharma, ORNL

Mengdawn Cheng, ORNL

Sharon S. Chen, LBNL

Victoria Demarest, Dow Chemical

William Fabiny, Dow Chemical

Hugo Destaillats, LBNL

Ronnen Levinson, LBNL

Date Published: March 4, 2016

\author{
Prepared by \\ OAK RIDGE NATIONAL LABORATORY \\ Oak Ridge, Tennessee 37831-6283 \\ managed by \\ UT-BATTELLE, LLC \\ for the \\ US DEPARTMENT OF ENERGY \\ under contract DE-AC05-00OR22725
}

Approved for Public Release 


\section{Abstract}

Highly water-resistant and solar-reflective coatings for low-slope roofs are potentially among the most economical retrofit approaches to thermal management of the building envelope. Therefore, they represent a key building technology research program within the Department of Energy. Research efforts in industry and the Department of Energy are currently under way to increase long-term solar reflectance on a number of fronts. These include new polymer coatings technologies to provide longer-lasting solar reflectivity and improved test methodologies to predict long-term soiling and microbial performance. The focus on long-term improvements in soiling and microbial resistance for maximum reflectance does not address the single most important factor impacting the long-term sustainability of low-slope roof coatings: excellent water resistance. The hydrophobic character of asphaltic roof products makes them uniquely suitable for water resistance, but their low albedo and poor exterior durability are disadvantages. A reflective coating that maintains very high water resistance with increased long-term resistance to soiling and microbial activity would provide additional energy savings and extend roof service life.

\section{Statement of objectives}

As part of the Department of Energy's (DOE) US-China Clean Energy Research Center for Building Energy Efficiency (CERC BEE), there is high interest in both the United States and China in exploring technology development that could lead to better-performing coatings for cool roof applications in both countries. Currently within CERC BEE, there is a joint work plan with China entitled "Cool Roofs"; under it the US side of CERC BEE has funded Project B-3, "Cool Roofs and Urban Heat Islands," and the China side has funded Project 3-6 at Chongqing University.

Under this project, new technology approaches are being explored for improving the water resistance of cool roof coatings, with possible generation of intellectual property beneficial to cool roof technology for both the United States and China. Researchers at Dow Chemical Company offer expertise in polymer design, coating formulation, and exterior durability. In the proposed program, the water resistance characteristics of highly reflective commercial and experimental roof coatings will be identified with the aim of understanding the material and chemical parameters necessary for improving their long-term water resistance in global environments. Understanding the effects of water (i.e. absorption, migration, permeability and adhesion), heat, light, age and ultraviolet (UV) light on key long-term solar reflective properties will allow the invention and commercialization of proprietary roof coating technologies. These will result in better-performing, long-term solar reflectance technologies that can effectively double cool roof technology energy savings. These technologies would allow DOE to establish higher reflectivity performance standards for the US market, as well as harmonize the standards in China to these higher performance levels through ongoing CERC BEE Project B-3.

\section{Benefits to the Mission of the Funding DOE Office}

The benefits of cool roofs - including building energy savings, urban heat island mitigation, smog abatement, reduction of peak power demand, and global cooling (negative radiative forcing resulting from the higher albedo of a reflective roof) - have been extensively studied and documented in the United States over the past 20-30 years. The results have led to the adoption of cool roof requirements in a variety of building energy efficiency standards, such as IECC (International Energy Conservation Code) 2012, ASHRAE 90.1, and California Title 24; cool roof incentives in voluntary energy efficiency programs, including Energy Star and Leadership in Energy and Environmental Design; and utility rebates. The Cool Roof Rating Council rates and labels the performance of thousands of cool roofing products now made by US manufacturers. This combination of scientific research, code requirements, incentive programs, third-party ratings, and product availability have made cool roofs a straightforward and 
important strategy for improving building energy efficiency and the urban environment in the United States, as well as for cooling the planet.

Solar-reflective cool roofs are used in the United States to (a) decrease energy use, energy cost, and greenhouse gas (GHG) emissions via both reduced solar heat gain and lower outside air temperatures; (b) offset GHG emissions via negative radiative forcing; and (c) improve air quality and human health by reducing outside air temperatures.

\section{Technical Discussion of Work Performed by All Parties}

The technical objective of the project was to develop high-performance cool roof coatings that are longlived and resistant to soiling in high-humidity, high-temperature environments. Dow and Oak Ridge National Laboratory (ORNL) developed an environmentally friendly, superhydrophobic (SH) materialbased, anti-soiling, cool roof coating. Lawrence Berkeley National Laboratory (LBNL), ORNL, and Dow performed a series of accelerated exposure tests and water repellency measurements to ensure that the coatings meet long-term durability requirements. Specifically, the team demonstrated enhanced water repellency (defined as a coating water contact angle of $150^{\circ}$ or greater) and enhanced soil resistance (defined as a $10 \%$ or less reduction in albedo after 9 months of environmental exposure). ORNL provided various silica-based powders functionalized to produce extreme water repellency and good binding to cool roof coatings developed by Dow. LBNL, Dow, and ORNL evaluated the performance of prototype coatings using accelerated testing techniques. This section lists and discusses the project tasks .

\section{Year 2013}

Development of environmentally friendly, superhydrophobic (SH) material-based, anti-biofouling white cool roof coatings for cool roofs and heat island mitigation in China and US.

ORNL and Dow personnel continued to hold detailed technical discussions regarding SH powder formulations, methods to incorporate these powders, mixture fabrication, and coating testing procedures. ORNL and LBNL personnel gave a joint cool roofs presentation to the US-China CERC-BEE Research/Demonstration Workshop in Wuhan, China, in late October. Scott Hunter and fellow ORNL meeting attendees visited the new Chinese Academy of Building Research facilities presently under construction in Beijing, where the implementation of various energy efficiency technologies was discussed. ORNL researchers evaluated and discussed with Dow personnel the studies of SH extender (SHE) mixing and dispersability performed by Dow. Based on these discussions, ORNL fabricated new silica-based SHE powders with different shapes and structural dimensions. Representative scanning electron microscopy (SEM) images of the SH particles are shown in Figure 1.
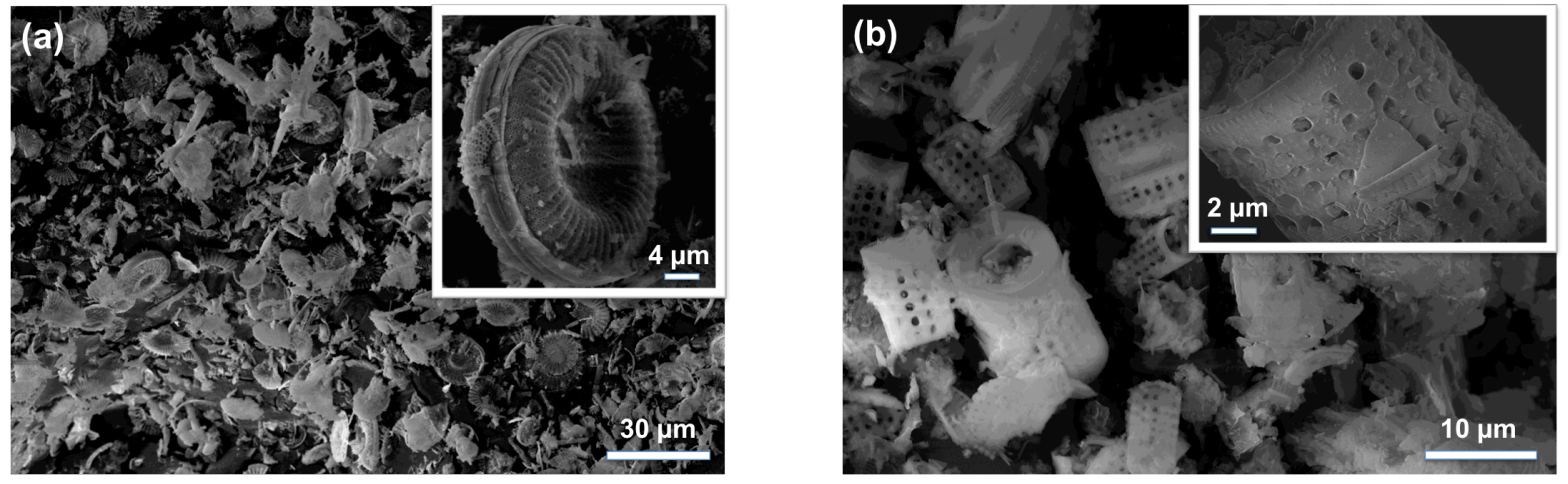

Figure 1. SEM images of (a) circular and (b) cylindrical diatomaceous earth SH particles. The inset images show the structure of individual particles at higher magnification. 
ORNL initiated several anti-biofouling studies using solvent-based water-repellent SH coatings. We developed an accelerated microbial testing protocol and test facility to test proposed new modified SH materials and coatings. ORNL and Dow personnel had detailed technical discussions of SH powder formulation manufacturing and testing. ORNL initiated several new anti-biofouling studies using surfacemodified SH coatings. These studies are summarized in the following paragraphs.

\section{Accelerated Microbial Aging Protocol}

- ORNL developed a mixture of microbial species for accelerated aging tests of cool roof samples.

- The test protocol was shown to be capable of reducing the optical performance of cool roofs to a level equivalent to that specified by the Environmental Protection Agency's EnergyStar requirements and of doing so in only a couple of months, a much shorter period than 3 years.

- The protocol will benefit from more tests on different cool roof coatings and substrates.

- An article was published in the Journal of Buildings Physics, ${ }^{1}$ and a provisional patent was filed by ORNL in February 2014.

The microbial aging procedure is summarized in the flow chart in Figure 2.

\section{Flow Chart for ORNL Microbial Aging Procedure}

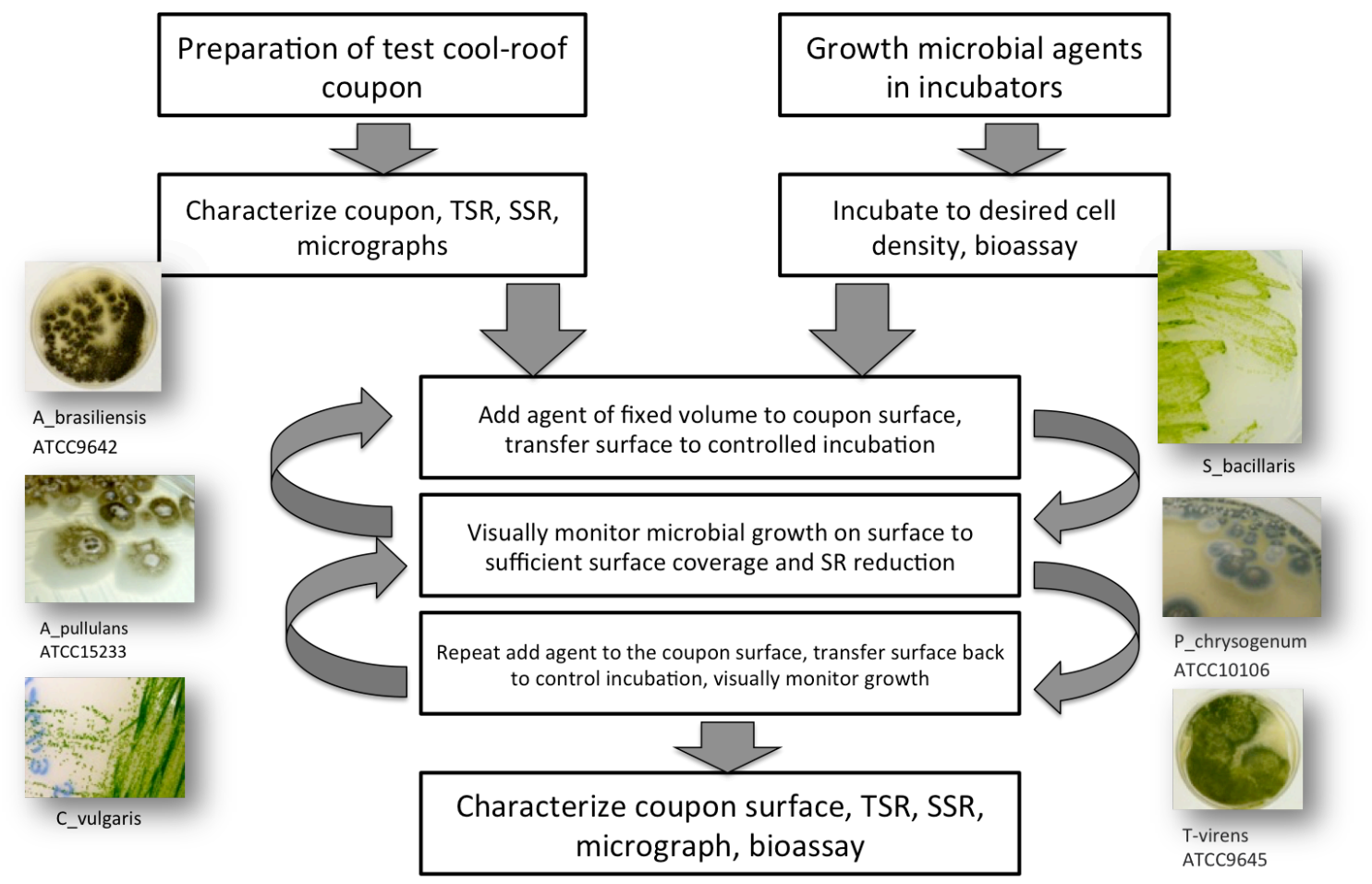

Figure 2. Microbial aging procedure developed at ORNL.

The results of the microbial aging studies show that

\footnotetext{
${ }^{1}$ Cheng M-D, Allman, SL, Graham, DE, Cheng, KR, Pfiffner, SM, Vishnivetskaya, TA, Desjarlais, AO. Surface reflectance degradation by microbial communities. Journal of Building Physics 2015. DOI:

$10.1177 / 1744259115611866$
} 
- Formation of biofilms on a cool roof coating is ubiquitous, independent of the surface.

- Biofilms can degrade the optical performance of cool roof surfaces.

- The biofilm does not have to destroy the coating or coating structure to degrade the optical performance.

- Preliminary tests on solvent-prepared SH coatings showed that the original ORNL microbial aging protocol could be applied.

- A biofilm was successfully grown on the surfaces of the SH coating in 2-3 weeks, and the biofilm growth continued under proper incubation conditions.

- Biofilm growth was confirmed within 2 weeks. The reduction in solar reflectance (measured by a D\&S reflectometer) varied widely from a few percentage points to $19 \%$ at the end of 2 months of exposure.

- SH silica particle-coated surfaces were found to be microscopically transformed by a microbial mixture in a manner similar to other coated surfaces.

\section{Complete formulation and SH testing of basic formulations and coating}

LBNL and ORNL evaluated solvent-based SH anti-soiling coatings fabricated by ORNL to understand anti-soiling and microbial growth properties of very water-repellent surfaces.

\section{Evaluate the anti-soiling ability of SH coatings}

The hydrophobicity, anti-soiling, and aging properties of the Dow fabricated coatings were evaluated at ORNL, LBNL, and Dow. The coatings were found to have low hydrophobicity because the SH silica particles were fully encapsulated in the polymer matrix. In contrast, the very SH solvent-based coatings provided by ORNL were found to have significant anti-soiling behavior in the LBNL tests.

Characterize surface roughness and topographical features, perform depth profiling measurement of water retention and coating oxidation

Surface roughening and abrasion studies performed at LBNL on the Dow provided anti-soiling coated coupons showed increased hydrophobicity and surface roughening as some of the buried SH silica particles were exposed at the coating surface. The studies continued at ORNL and LBNL.

\section{Measurement of water contact angle and accelerated durability testing}

ORNL and Dow prepared anti-soiling coated coupons containing varying concentrations of SH silica powders. These coupons were evaluated at LBNL, along with reference materials, to simulate field exposure for different time lengths ( 3 years and 5 years). ${ }^{2}$

All coatings had very high dirt resistance and excellent strength, but poorer than expected water repellency and swelling due to the encapsulation of the silica particles within the resin matrix.

\section{Year 2014}

Measurement of water contact angle and accelerated durability testing

\footnotetext{
${ }^{2}$ Sleiman M, Kirchstetter TW, Berdahl P, Gilbert HE, Quelen S, Marlot L, Preble CV, Chen S, Montalbano A, Rosseler O, Akbari H, Levinson R, Destaillats H. Soiling of building envelope surfaces and its effect on solar reflectance - Part II: Development of an accelerated aging method for roofing materials. Solar Energy Materials \& Solar Cells 2014, 122, 271-281.
} 
Experiments to optimize the LBNL goniometer and ancillary setup were completed. ORNL and Dow prepared specimens of coatings containing SH materials; those specimens were tested at LBNL along with reference materials to simulate field exposure for different time lengths ( 3 years and 5 years), as well as mechanical abrasion to facilitate access of the SH pigments to the surface.

\section{$U V$ weathering, water repellency, and accelerated durability testing of new cool roof coatings}

Accelerated UVA exposure studies were performed at LBNL on the ORNL and Dow fabricated antisoiling coated coupons.

\section{Complete anti-soiling coating formulation and SH and optical testing of coatings}

Dow pursued studies to expose the SH particles at the surface of the anti-soiling coatings, minimizing the encapsulation of the silica particles within the resin.

\section{Measurement of water contact angle and accelerated durability testing.}

ORNL and Dow prepared anti-soiling coated coupons containing varying concentrations of SH silica powders. These coupons were evaluated at LBNL, along with reference materials, to simulate field exposure for different time lengths ( 3 years and 5 years). Mechanical abrasion studies were also performed to facilitate access of the SH silica particles at the surface of the coatings. The preliminary results from these analyses and possible further studies were discussed by LBNL, ORNL, and Dow.

ORNL prepared and provided DOW with additional SH particulates based on silica. The sizes of the particulates varied from sub-micron to tens of microns.

\section{Year 2015}

ORNL synthesized SH silica particles with controlled sizes and surface features. Testing coupons were coated with SH particles of different sizes and geometries. ORNL provided coated coupons to LBNL for further testing. The synthesized particles are shown in Figure 3.
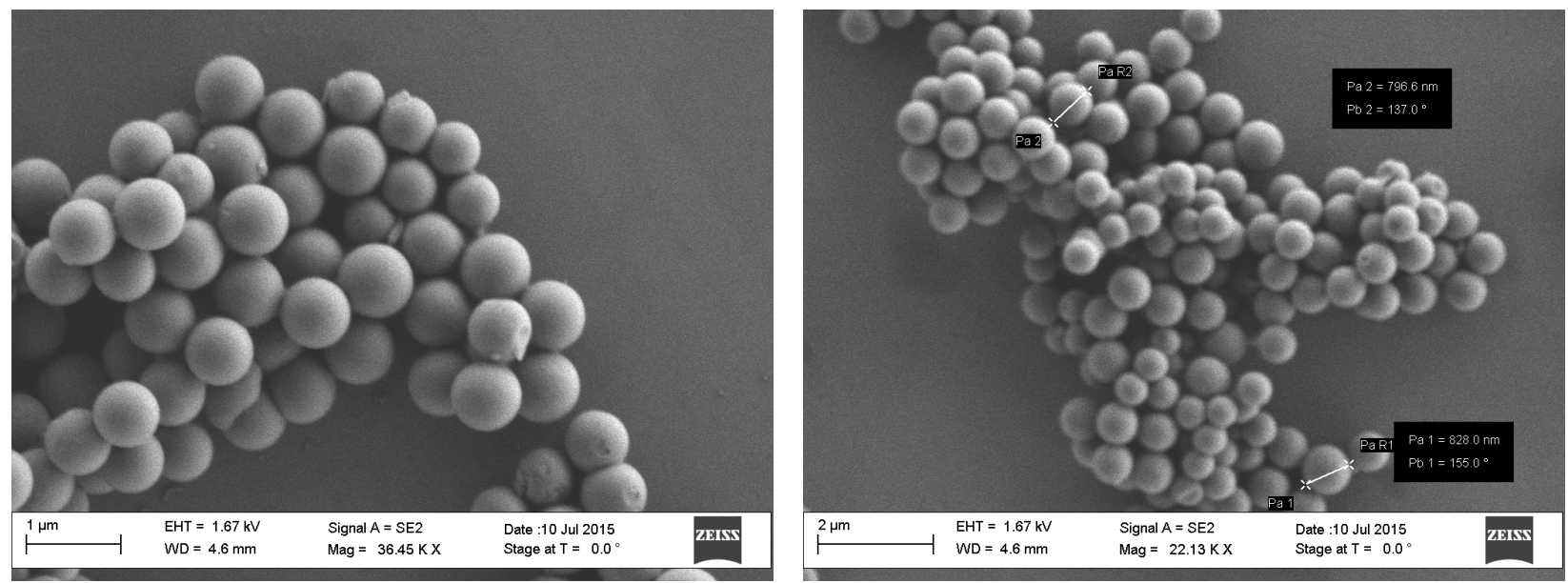

Figure 3. Synthesized silica particles with controlled sizes.

- Particles with well-defined sizes and geometries were synthesized

- The diameter $(\sim 800 \mathrm{~nm})$ of the individual particles was in good agreement with the particle size analysis measurements 
ORNL and Dow prepared anti-soiling coated coupons containing varying concentrations of SH silica powders. These coupons were evaluated at LBNL, along with reference materials, to simulate field exposure for different time lengths ( 3 years and 5 years). The coated coupons are shown in Figure 4.
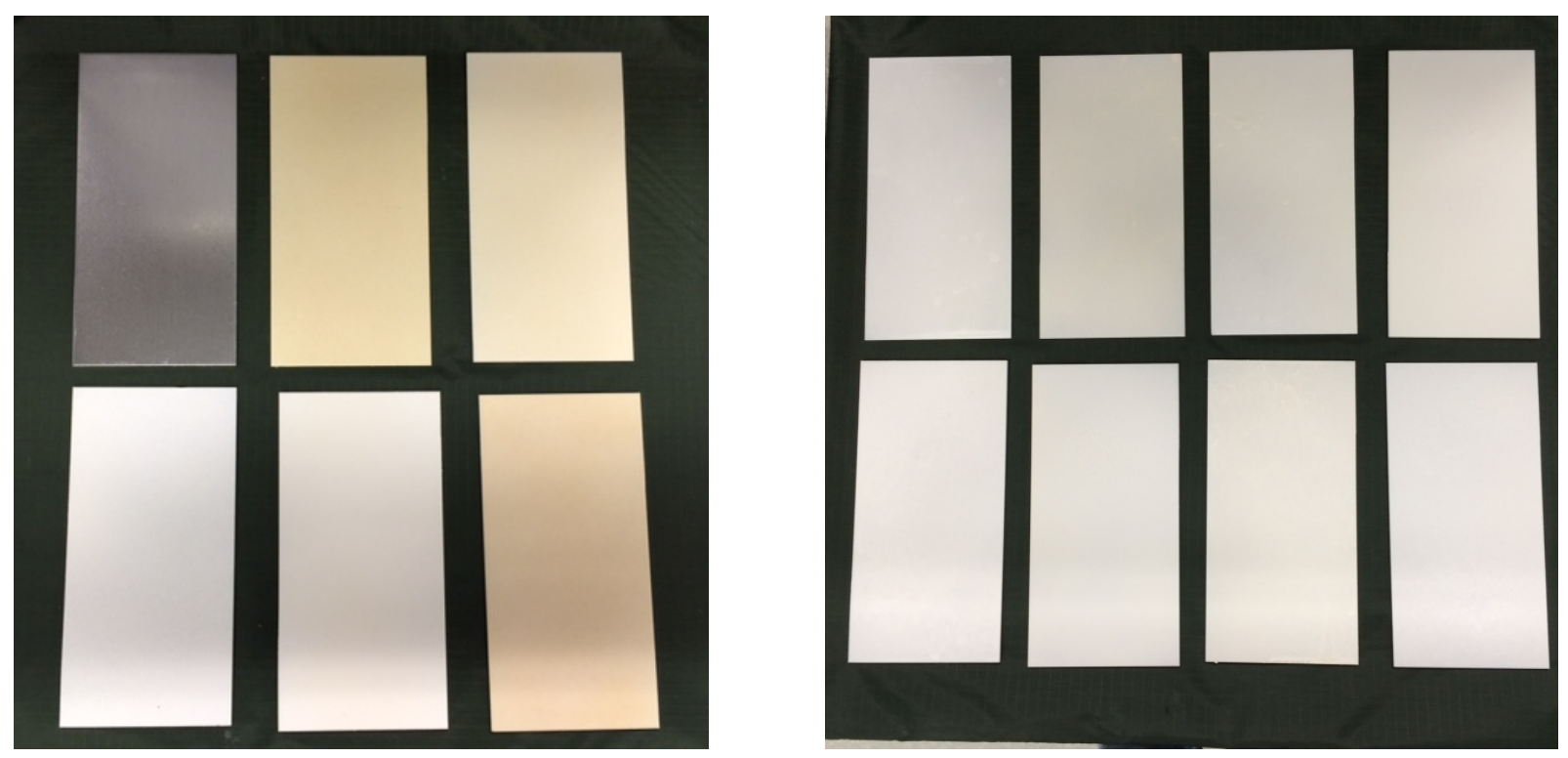

Figure 4. Images of two different series of coupons that were evaluated at LBNL. The water contact angle (WCA) values of the coupons that were coated with polymer binders (control samples) were approximately $90^{\circ}$. The WCA values of the coupons coated with SH particles varied from $150^{\circ}$ to $170^{\circ}$.

Figures 5 and 6 illustrate results obtained at LBNL for coatings prepared by ORNL. Figure 5 shows the solar reflectance of coatings before and after being subjected to a laboratory accelerated procedure to simulate 3 years of natural exposure in the United States (ASTM D7897). The water contact angle was measured on the same specimens before and after accelerated aging, and the values are reported in Table 6 , together with contact angles measured by ORNL for the same coatings. The table below each figure summarizes the relative changes in solar reflectance $\left(\Delta \mathrm{SR} / \mathrm{SR}_{\mathrm{i}}\right)$ or in water contact angle $(\Delta \mathrm{WCA} / \mathrm{WCA})_{i}$, which were found to change proportionally, in most cases. 


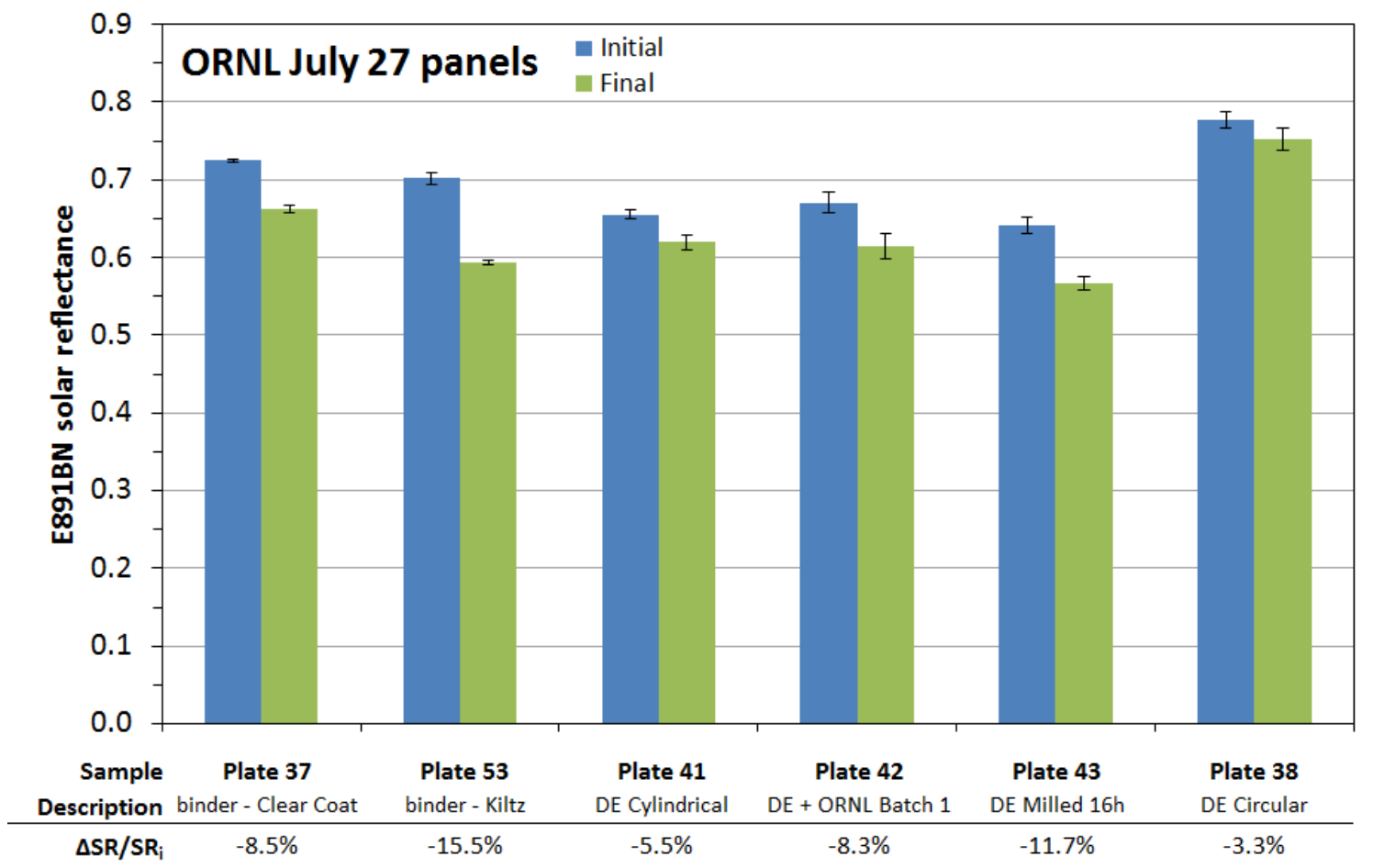

Figure 5. Solar reflectance of coatings prepared by ORNL before and after accelerated aging at LBNL.

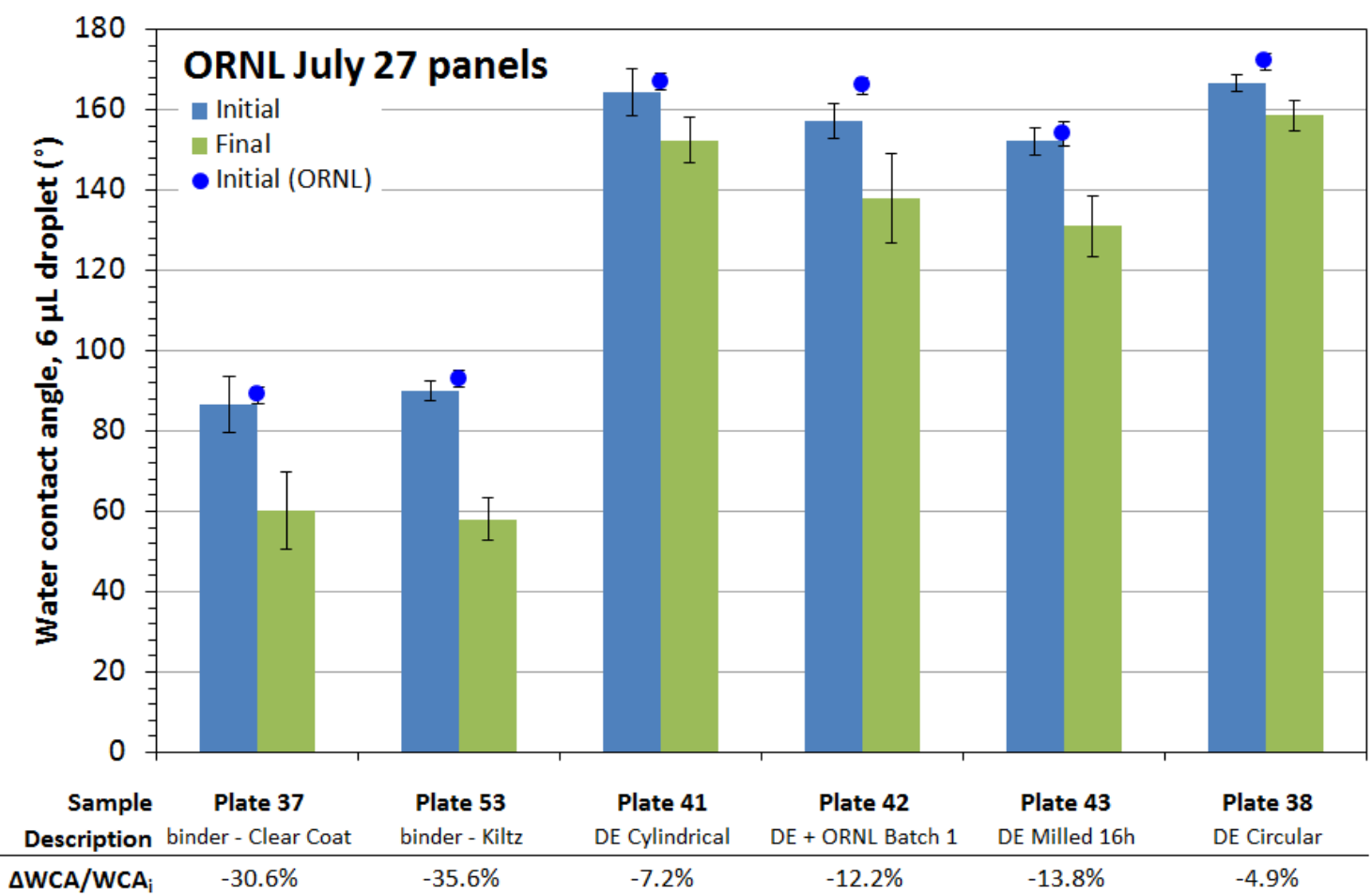
LBNL.

Figure 6. Water contact angle of coatings prepared by ORNL before and after accelerated aging at 
Evaluate commercially available DE superhydrophobic powders for cool roof application.

Dow developed several application approaches for dispersing SH diatomaceous earth (DE) particles into a polymer matrix. ORNL prepared SH testing coupons based on commercially available DE particles of different sizes and geometries.

Evaluate the water repellency, self-cleaning ability, and water permeation of the superhydrophobic coatings.

Dow prepared samples based on the SH DE particles. The samples were sent to LBNL for testing and evaluation.

ORNL synthesized and provided Dow with additional SH particulates based on silica. ORNL prepared SH testing coupons based on two different types of silica particles that were synthesized using sol-gel techniques. The powders were characterized using scanning electron microscopy and particle size analysis techniques. The water repellency properties of the coupons were measured using contact angle measurements. The results obtained by Dow and ORNL indicate that the performance of the coatings is associated with the ability of the SH particles to diffuse and migrate to the top of the coating (polymer air interface).

\section{Accelerated UV weathering and water repellency of new cool roof coatings}

The ORNL coating based on SH particulates showed the best performance, according to the LBNL testing results. According to the LBNL aging tests equivalent to 3 years of natural exposure (ASTM D7897), the ORNL SH coating demonstrated a 3.3 and $4.9 \%$ reduction in the solar reflectance and the water contact angle, respectively. It was the best-performing coating in terms of weathering durability and in terms of properties. The initial values of the solar reflectance and water contact angle were 0.778 and $167^{\circ}$, respectively. Based on these results, ORNL is preparing additional samples.

Continued accelerated coating testing and formulation optimization based on ongoing coating durability studies

Based on LBNL's accelerated aging results, ORNL fabricated a series of additional samples. The samples were shipped to LBNL for further testing.

\section{Subject inventions}

Patent applications:

1. US 2014/0090578 A1, "Method of Making Superhydrophobic/ Superoleophilic Paints, Epoxies and Composites," John Simpson and Scott Hunter, filing date February 1, 2013, publication date April 3, 2014.

2. US 2014/0155522 A1, "Durable Superhydrophobic Coatings," John T Simpson, Georgios Polyzos, and Daniel A. Schaeffer, filing date March 11, 2013, publication date June 5, 2014.

3. US 2014/0094540 A1, "Superhydrophobic Powder Coatings," John T. Simpson, filing date September 28, 2012, publication date April 3, 2014. 


\section{Commercialization Possibilities}

The development of water-resistance and solar-reflective coatings can benefit several applications in the residential and commercial building industry. Our industrial partner Dow Chemical is working on the dispersion of the particles into polymer matrices. For this technology to be successfully commercialized, the SH coatings must be solvent-free and exhibit good dispersion properties.

\section{Plans for Future Collaboration}

The evaluation of the coatings and the coating application procedures are in progress. Depending on the final results and the technical risks future collaborations can be beneficial in order to develop solvent-free coatings. Moreover, additional studies can be performed to evaluate the microbial effects on paint binders and assess their performance under multiple climate conditions such as temperature and humidity.

\section{Conclusions}

During this CRADA, several coating formulations were developed and tested. According to the LBNL aging testing that is equivalent to 3 years of natural exposure (ASTM D7897), the ORNL SH coating demonstrated 3.3 and $4.9 \%$ reductions in solar reflectance and the water contact angle, respectively. The initial values of the solar reflectance and water contact angle were 0.778 and $167^{\circ}$, respectively.

Eliminating the use of solvents and improving the dispersion of the particles is necessary to scale up the coatings and make them viable for commercial applications. 